\title{
Guiding catheter extension compatibility for high speed rotational atherectomy
}

\author{
Tomasz Pawłowski, Paweł Modzelewski, Michał Stachura, Zbigniew Śliwiński, Robert J. Gil \\ Department of Invasive Cardiology, CMKP, Warsaw, Poland
}

Adv Interv Cardiol 2021; 17, 2 (64): 210-213

DOI: https://doi.org/10.5114/aic.2021.107502

\section{Introduction}

Coronary calcification is one of the features that characterize atherosclerosis. The location of a calcific plaque may vary from case to case [1]. Some distal locations may affect procedural outcomes of coronary angioplasty, resulting in impaired device deliverability. In these cases, guiding extension catheters have been widely introduced into practice to overcome the problem of poor deliverability and guiding catheter support. In some patients, calcified lesions are located distally and rotational burr deliverability is also impaired.

The aim of this study was to test the commercially available guiding extension catheters in terms of compatibility of these devices with rotational atherectomy burrs outside the patient's body.

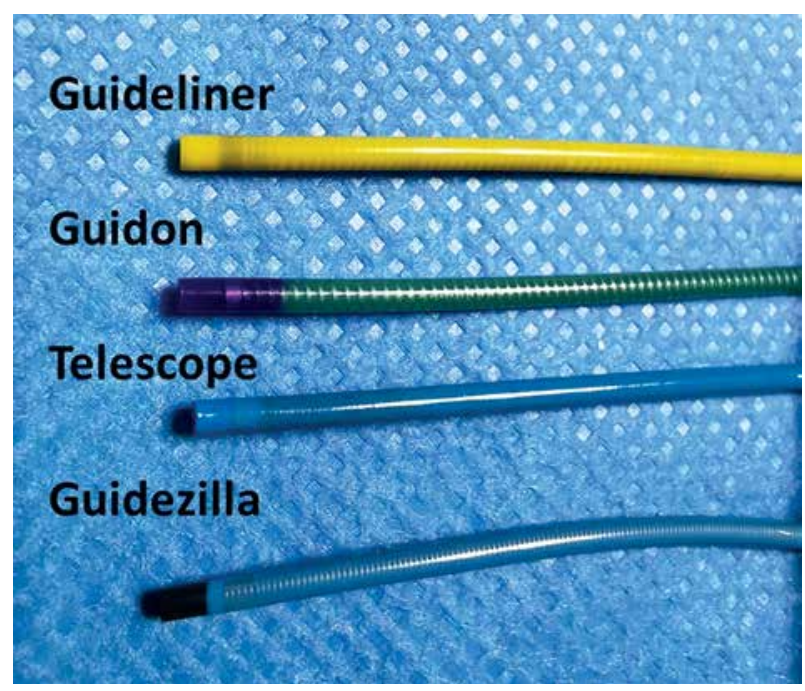

Figure 1. Set of commercially available guiding catheter extensions. From top to bottom: Guideliner (Teleflex Co), Guidon (IMDS Co), Telescope (Medtronic Co), Guidezilla (Boston Scientific Co)

\section{Material and methods and results}

We tested in vitro compatibility of commercially available guiding extension catheters with Rotablator burrs sized $1.25 \mathrm{~mm}$ and $1.50 \mathrm{~mm}$. We put 7 French guiding catheters (Launcher, Medtronic Co) into a wet environment as a platform for our testing. Both 6 and 7 Fr guiding extensions were selected for the testing: Guideliner (Teleflex Co), Guidon (IMDS Co), Guidezilla (Boston Scientific Co) and Telescope (Medtronic Co). An overview is presented in Figure 1 and Table I.

The extension catheters were flushed with saline and introduced into the guiding catheter over the Rotablator guidewire (Boston Scientific Co). Using the guidewire, we tried to insert first a $1.25 \mathrm{~mm}$ burr and then a $1.50 \mathrm{~mm}$ burr. They were advanced forward using DynaGlide mode at 80000 revolutions per minute. When attempting the $1.25 \mathrm{~mm}$ burr, only in the $6 \mathrm{Fr}$ Telescope extension it was impossible to introduce the burr into the extension (Figure 2). In 2 cases, we observed resistance during forward and backward movement (6 Fr Guideliner and 6 Fr Gui-

Table I. Guiding extension catheter inner sizes as reported by manufacturers

\begin{tabular}{lc}
\hline Guiding extension name & Inner size [mm] \\
\hline Telescope 6 Fr & 1.42 \\
\hline Telescope 7 Fr & 1.57 \\
\hline Guideliner 6 Fr & 1.42 \\
\hline Guideliner 7 Fr & 1.57 \\
\hline Guidon 6 Fr & 1.42 \\
\hline Guidon 7 Fr & 1.57 \\
\hline Guidezilla 6 Fr & 1.45 \\
\hline Guidezilla 7 Fr & 1.60
\end{tabular}




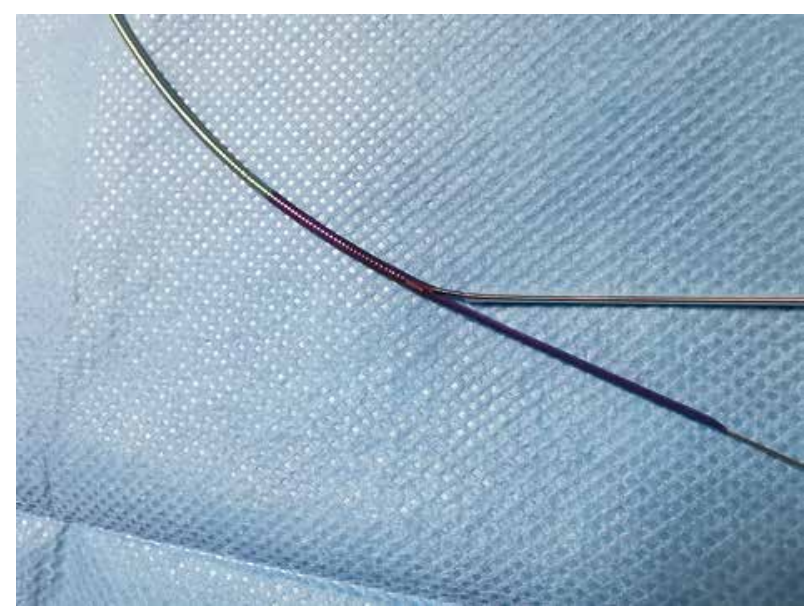

Figure 2. Picture of $6 \mathrm{Fr}$ extension - Telescope 1.25 burr does not pass through (on the left). Note that the olive is inside but the burr sleeve does not pass through the guide extension

don). In all $7 \mathrm{Fr}$ variants, the $1.25 \mathrm{~mm}$ burr passed easily. Our practice recommendations are presented in Table II. Graphic examples of in vitro testing are presented in Figure 3.

None of the 6 tested Fr extensions were compatible with the $1.50 \mathrm{~mm}$ burr, but all available items in $7 \mathrm{Fr}$ size provided enough lumen for the 1.50 burr.

Of note, one should remember that the outer diameter of a Rotablator burr (i.e. the transparent sleeve) is $1.45 \mathrm{~mm}$ (measured by us, using professional calipers, performed by two researchers). All tested extensions have inner size data on the producer's box. Juxtaposition of compatibility of guide extensions is presented in Table I.

\section{Discussion and conclusions}

Calcified distal coronary lesion treated by coronary angioplasty remains a huge challenge for every interventional cardiologist. Limited technical features of rotational atherectomy were a significant hindrance to using it for this location. So far, the commercially available system for high speed rotational atherectomy has used a special advancer that allows one to perform a movement of about $7 \mathrm{~cm}$. Of course, for many distal locations, it is too short to reach the lesion if the operator parks the burr just outside the guiding catheter. One knows that non-significant calcifications along the artery may affect the risk of the burr getting stuck if delivered during "dyna mode". In this scenario, the operator should safely advance the burr as far as possible and start the rotablation at the closest point to the lesion.

The idea to use guiding catheter expansion to allow rotational atherectomy to be performed in a distal coronary lesion [2] or increase guiding catheter support [3] is not new. To our best knowledge, this is the first report comparing different guide catheter extensions
Table II. Practical recommendations regarding guiding catheter size and available extensions

\begin{tabular}{|c|c|c|}
\hline Burr size & 6 Fr catheter & $7 \mathrm{Fr}$ catheter \\
\hline $1.25 \mathrm{~mm}$ & $\begin{array}{c}\text { Guidezilla } \\
\text { Guideliner* } \\
\text { Guidon* }\end{array}$ & $\begin{array}{l}\text { Telescope } \\
\text { Guideliner } \\
\text { Guidon } \\
\text { Guidezilla }\end{array}$ \\
\hline $1.50 \mathrm{~mm}$ & None & $\begin{array}{l}\text { Telescope } \\
\text { Guideliner } \\
\text { Guidon } \\
\text { Guidezilla }\end{array}$ \\
\hline
\end{tabular}

${ }^{*}$ Forward and backward resistance during movement.

with respect to feasibility of rotational atherectomy burr deliverability. In our daily practice, we have faced this situation quite often, but several attempts during coronary angioplasty failed because of burr friction or getting stuck as well as mismatching of these two components. Using commercially available extensions and two sizes of rotablation burr $(1.25$ and $1.50 \mathrm{~mm})$ we found that there is a mismatch between producer declaration regarding inner size of the device and possibility of burr advancement deep into the extension. Theoretically, all extensions should be well fitted with a $1.25 \mathrm{~mm}$ burr, but in our tests two of them failed. Two of the $6 \mathrm{Fr}$ extensions (Guideliner and Guidon) are able to host the $1.25 \mathrm{~mm}$ burr but with perceptible friction. Of course, in in vivo circumstances, it could lead to problems with burr advancement. One should note that aorta or large arterial vessel kinking may lead to the burr getting stuck.

The only extension which works with the $1.25 \mathrm{~mm}$ burr is the Guidezilla 6 Fr. The above-mentioned extensions that provide friction could be recommended only in bail-out situations or vessels that are not able to accept 7 Fr devices.

It seems that all $7 \mathrm{Fr}$ devices cooperate with the $1.50 \mathrm{~mm}$ burr without any problems. Unfortunately, none of the tested devices provide any space for the $1.75 \mathrm{~mm}$ burr, mainly due to the large diameter of the transparent sleeve.

In conclusions, we would like to stress that in terms of $6 \mathrm{Fr}$ guiding extensions, only the Guidezilla (Boston Scientific) shows good cooperation with the $1.25 \mathrm{~mm}$ burr and all $7 \mathrm{Fr}$ work with both sizes. Using a dedicated guiding extension may facilities a coronary rotablation in a distal coronary location that was recently presented by our group during a live cardiology meeting.

As mentioned earlier, we can recommend the use of extension catheters during coronary rotablation in two particular cases: first, when the burr should be parked in the mid portion of the calcified artery (with risk of the burr getting stuck), and then it is performed within the extension catheter; second, if the guiding catheter support is too low and needs to be increased by an extension catheter. Of course, one should remember that 

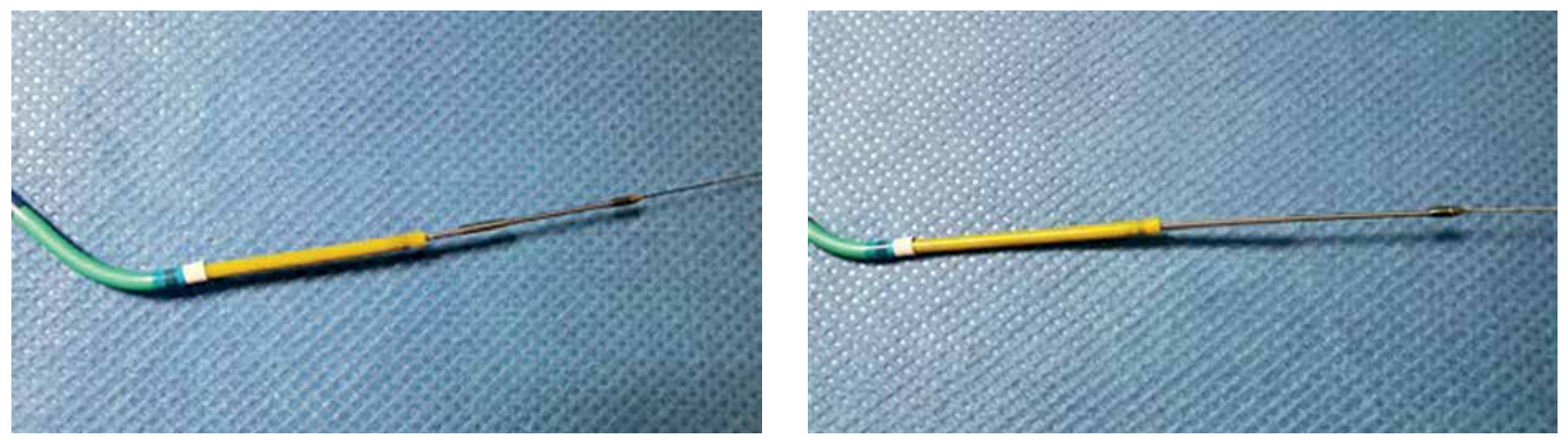

Guideliner 7 Fr (Teleflex Co) - 1.25 mm (left); 1.5 mm (right)
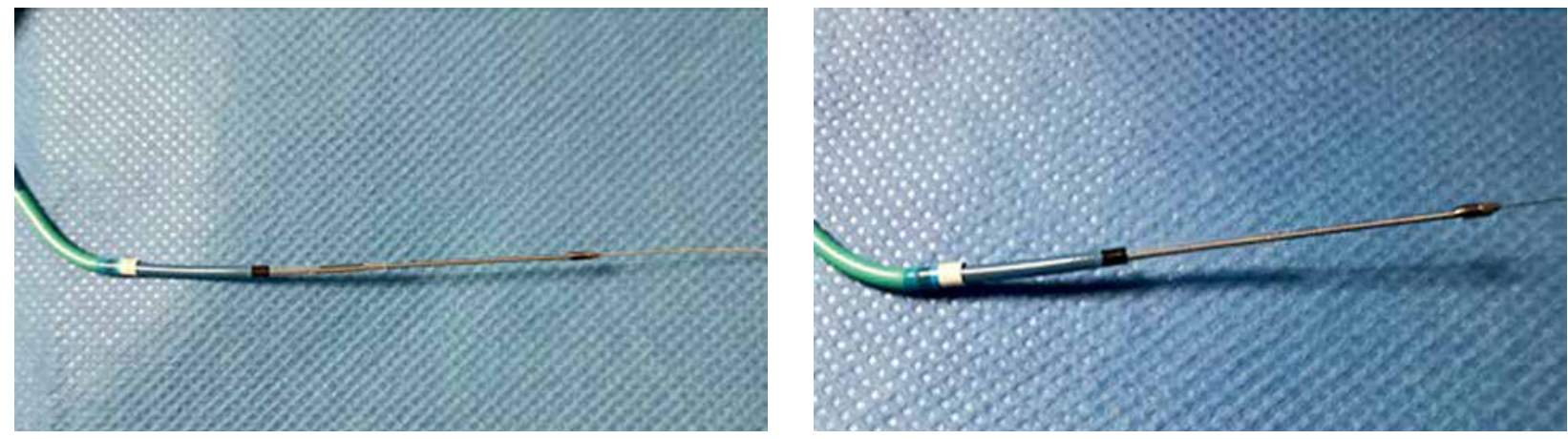

Guidon $7 \mathrm{Fr}$ (IMDS Co) - 1.25 mm (left); 1.5 mm (right)
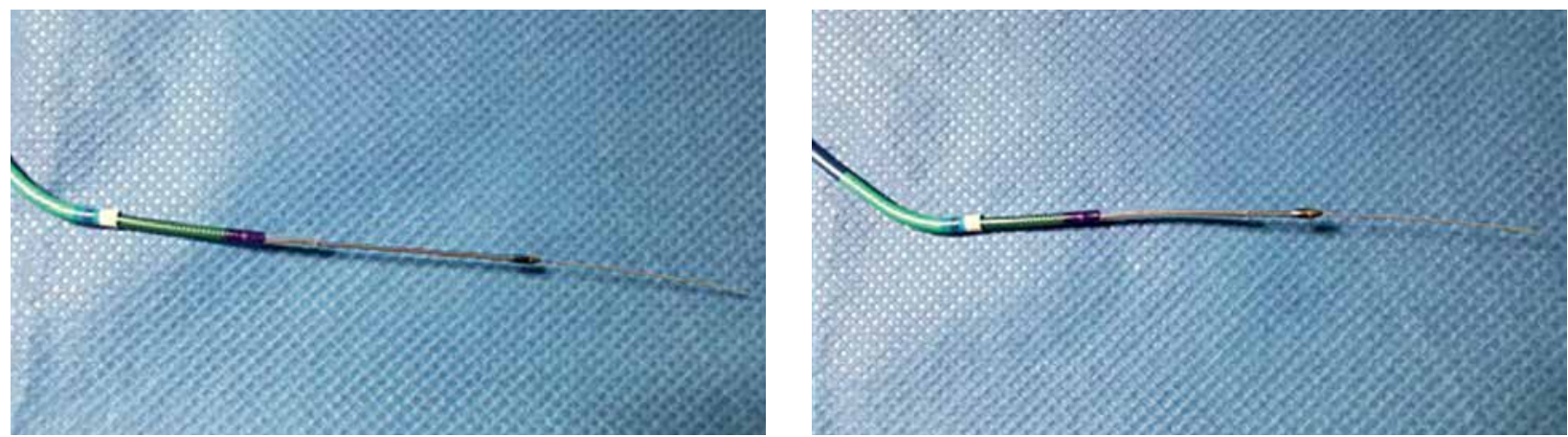

Telescope $7 \mathrm{Fr}$ (Medtronic Co) - 1.25 mm (left); 1.5 mm (right)
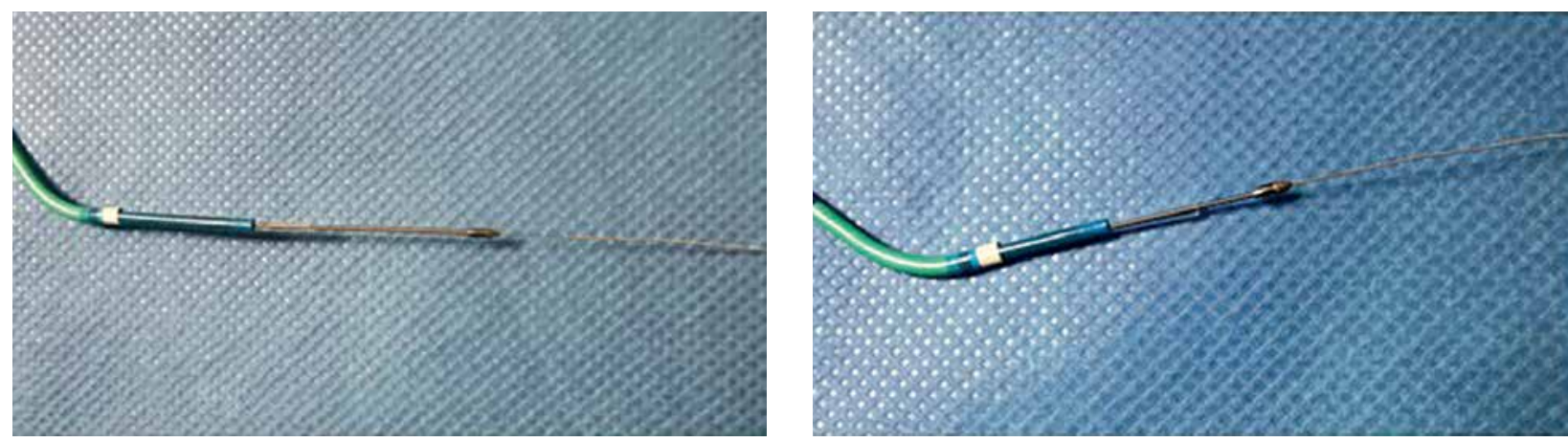

Guidezilla $7 \mathrm{Fr}$ (Boston Scientific Co) - 1.25 mm (left); 1.5 mm (right)

Figure 3. Comparison of $7 \mathrm{Fr}$ guide extensions with $1.25 \mathrm{~mm}$ and $1.50 \mathrm{~mm}$ burrs that passed easily during tests 
use of a guiding extension for rotational atherectomy is currently off-label and even in tested devices should be used with caution to prevent damage of the extension catheter. For that reason, we recommend slow use of DynaGlide mode to deliver the burr outside the extension.

\section{Conflict of interest}

The authors declare no conflict of interest.

\section{References}

1. Mintz G, Popma J, Pichard A, et al. Patterns of calcification in coronary artery disease. A statistical analysis of intravascular ultrasound and coronary angiography in 1155 lesions. Circulation 1995; 91: 1959-65.

2. Vo M, Minhas K, Kass M, Ravandi A. Novel use of the GuideLiner catheter to deliver rotational atherectomy burrs in tortuous vessels. Case Rep Cardiol 2014; 2014: 594396.

3. Costanzo P, Aznaouridis K, Hoye A, Alahmar A. Guide-liner-facilitated rotational atherectomy in calcified right coronary artery. The "child" makes the difference. JACC Interv 2016; 9: e47-8. 